\title{
Embriogénesis somática en madroño (Arbutus xalapensis)
}

\author{
Somatic embryogenesis of madrone (Arbutus xalapensis)
}

\author{
Violeta Tovar Rocha a , Patricia Delgado Valerio a, Alejandro Martínez Palacios ${ }^{\text {b }}$, Julio C Tovar Rocha ${ }^{\text {a }}$ \\ José López Medina a, María del Carmen Rocha Granados a*
*Autor de correspondencia: a Universidad Michoacana de San Nicolás de Hidalgo, Facultad de Agrobiología "Presidente Juárez", Paseo de la Revolución S/N, Esquina Berlín, Col Viveros, C.P. 60190, Uruapan, Michoacán, México, tel: +52-452-52-36474, crochagra@hotmail.com \\ ${ }^{\mathrm{b}}$ Instituto de Investigaciones Agropecuarias y Forestales (IIAF), Morelia, Michoacán, México.
}

\begin{abstract}
SUMMARY
Somatic embryogenesis can be used for the rescue of threatened forest species. In this research work, the effect of the medium on the germination of Arbutus xalapensis zygotic embryos and 2,4-D growth regulator on induction of embryogenic callus was studied. Strawberry tree fruits were disinfested and the zygotic embryos of seeds were removed and put on MS, WPM and P889 mediums; while for induction of embryogenic callus, they were cultured on MS and WPM. The germination of embryos was affected substantially by culture medium used, being the WPM where $58 \%$ of germination of zygotic embryos was obtained, compared with P889 and MS with 0 and $2 \%$ germination, respectively. Zygotic embryos were placed on MS and WPM medium added with $0,1,2,4$ and 8 mg L - $^{-1}$ 2,4-D, under light and dark conditions for 30 days. Embryos cultured in MS, and left under low light conditions, had not effect to any treatment to which they were subjected; however, under darkness condition embryogenic callus formation was possible to be induced in the concentration of $1 \mathrm{mg} \mathrm{L}^{-1} 2,4-\mathrm{D}$, while on WPM in light condition, the formation and growth of embryogenic callus was achieved by adding $2 \mathrm{mg} \mathrm{L}^{-1}$; under darkness required only $1 \mathrm{mg} \mathrm{L}^{-1}$. Culture medium is essential for the germination of the embryos, the combination of culture medium, the concentration of 2,4-D and the condition of light or darkness are fundamental factors in the induction of embryogenic callus of strawberry tree, required for subsequent studies of micropropagation and cryopreservation of this species.
\end{abstract}

Key words: Madrone, Murashige and Skogge, Woody Plant Medium, Pullman 889, 2,4-Dichlorophenoxiacetic.

\section{RESUMEN}

El objetivo de este trabajo experimental fue estudiar el efecto del medio de cultivo sobre la germinación de embriones cigóticos de madroño y el efecto del 2,4-Diclorofenoxiacético (2,4-D) sobre la inducción de callo embriogénico. Para el primer caso, se extrajeron los embriones cigóticos de las semillas y colocaron en los medios Murashige y Skoog (MS), Woody Planta Medium (WPM) y Pullman 889; para la inducción de callo embriogénico sólo fueron utilizados el MS y WPM adicionados con 0, 1, 2, 4 y 8 mg L-1 de 2,4-D, bajo luz y oscuridad durante 30 días. En el medio WPM se obtuvo un $58 \%$ de germinación, mientras que en el P889 y MS sólo un 0 y $2 \%$ de germinación, respectivamente. Los embriones cultivados en el medio MS en luz no presentaron respuesta alguna en ningún de los tratamiento; sin embargo, en dicho medio pero en oscuridad se logró inducir la formación y crecimiento de callo embriogénico a $1 \mathrm{mg} \mathrm{L}^{-1}$ de 2,4-D, mientras que en el medio WPM en luz se logró con $2 \mathrm{mg} \mathrm{L}^{-1}$; y en oscuridad $1 \mathrm{mg} \mathrm{L}^{-1}$ de 2,4-D. Se concluye que el medio de cultivo es fundamental para la germinación de los embriones y la combinación del medio de cultivo, la concentración del 2,4-D y la condición de luz u oscuridad, son factores fundamentales en la inducción de callos embriogénicos de madroño, requeridos para estudios posteriores de micropropagación y criopreservación de la especie.

Palabras clave: madroño, Murashige y Skooge, Woody plant medium, Pullman 889, 2,4-diclorofenoxiacético.

\section{INTRODUCCIÓN}

En México, Arbutus xalapensis Kunth (Ericaceae), madroño, es una especie de importancia ecológica y económica, la cual hasta el momento ha sido poco investigada. Entre los problemas que enfrenta esta especie en el estado de Michoacán se encuentran la falta de estudios de métodos de propagación vegetativa eficientes, una severa deforestación, incendios, tala inmoderada y el cambio de uso de suelo por especies frutícolas como el aguacate (INADEF 2009). Por ello, la propagación y preservación de esta especie se hace necesaria, y aunque la diversidad genética de muchos cultivos ha sido bien preservada ex situ, muchos otros que son importantes a nivel nacional o local están pobremente representadas en las colecciones debido a diversas razones, entre las que destacan la producción de semillas recalcitrantes incapaces de soportar desecación o la sobre explotación de las especies lo que evita que lleguen a un estado 
de maduración idónea para la producción de semillas, para ello es importante idear nuevas técnicas que ayuden a su conservación (Villalobos-Arámbula y Engelmann 1995). El cultivo de tejidos vegetales es un conjunto de técnicas que permite la propagación in vitro de células, tejidos y órganos vegetales bajo condiciones controladas. Una de las características más notables del cultivo de tejidos vegetales, es que ciertas células totipotenciales, bajo condiciones idóneas de cultivo, tienen la capacidad de formar embriones somáticos mediante un proceso muy similar a la embriogénesis cigótica (Thorpe 2000). Existen dos tipos de embriogénesis somática in vitro, la directa (ESD) y la indirecta (ESI). En la embriogénesis directa, los embriones aparecen directamente sobre el explante original; mientras que en la indirecta, el primer paso indispensable en este proceso es la obtención de tejido calloso o bien, la suspensión celular embriogénica a partir de la cual se obtendrá la diferenciación de los embriones somáticos en un segundo paso (Quiroz et al. 2006).

Para utilizar estas técnicas es indispensable establecer el medio de cultivo más idóneo para cada especie, pues se ha observado que plantas como la guayaba (Psidium guajava L.) se propaga en forma masiva y de manera eficiente en un medio WPM (Woody Plant Medium) (Ocampo y Núñez 2007); por su parte, Hossain et al. (1993) lograron regenerar plantas completas de papaya (Carica papaya $\mathrm{L}$.) a partir de explantes de peciolos cultivados en medio MS (Murashige y Skoog 1962), Pullman et al. (2003b) promueven la iniciación y extrusión de embriones cigóticos de Pinus taeda L. en un medio P889. Martínez et al. (2004) indujeron la formación de callo y embriones somáticos en forma indirecta en hoja de eucalipto cultivados en medio B5 (Gamborg et al. 1970). Este medio es muy empleado en el cultivo de protoplastos y en la regeneración de diversas plantas, a diferencia del medio Nitsch y Nitsch (1969), establecido para la obtención de plantas haploides de Nicotiana sp. a partir de granos de polen. El efecto del medio de cultivo, la concentración de los reguladores de crecimiento y las condiciones de crecimiento de los callos in vitro han sido investigadas en plantas como Phoenix dactylifera L. (Eke et al. 2005), Phragmites australis (Cav.) Trin. ex Steud. (Lauzer et al. 2000, Cui et al. 2002), Eleusine indica L. (Yemets et al. 2003), Tylophora indica Burm. f. Merrill. (Jayanthi y Mandal 2001), Cynodon dactylon (L.) Kuntze (Ramgareeb et al. 2001) y Stenotaphrum secundatum (Walt.) Kunze (Li et al. 2006), donde se ha observado que explantes con tejidos suaves y jóvenes, expuestos a concentraciones de 1 a $3 \mathrm{mg} \mathrm{L}^{-1}$ de 2,4-D e incubados a temperaturas de 24 a $27^{\circ} \mathrm{C}$ en oscuridad, producen mayor cantidad de tejido calloso y masas proembrionarias conteniendo embriones somáticos en sus diferentes estados de desarrollo (globular, corazón, torpedo y cotiledonario).

La hipótesis de este trabajo es que los embriones cigóticos de madroño son órganos con tejidos jóvenes que permiten de manera eficiente la formación de callos embriogénicos. Así, el objetivo del presente estudio es determinar el efecto del medio de cultivo sobre la germinación in vitro de embriones cigóticos de madroño (intermedio y maduro), así como la concentración de auxina (2,4-D) y las condiciones de luz y oscuridad, requeridas en la inducción de callos embriogénicos de madroño.

\section{MÉTODOS}

Esta investigación se realizó en el laboratorio de Fisiología Vegetal de Plantas Leñosas de la Facultad de Agrobilogía "Presidente Juárez" de la Universidad Michoacana de San Nicolás de Hidalgo. Para los experimentos de efecto del medio de cultivo sobre la germinación, y de inducción de callos embriogénicos, fueron utilizados embriones cigótico de semillas provenientes de frutos en estado intermedio y maduro (Tovar et al. 2014).

Sitios de colecta. La colecta se realizó durante los meses de mayo a junio del 2012, en la localidad de San Miguel Charahuén, municipio de Pátzcuaro (N 1900'19,5” y O $101^{\circ} 51^{\prime} 05,2^{\prime \prime}$, altitud de 1.990 m s.n.m.).

Colecta de material vegetativo. Se colectaron racimos de frutos en distintos estados de maduración de 10 árboles reproductivos de 6 a $8 \mathrm{~m}$ de altura. Los racimos fueron colocados en bolsas de papel de estraza, etiquetándolas con el sitio y fecha de colecta, los cuales fueron almacenados en el laboratorio de Fisiología Vegetal de la Facultad de Agrobiología "Presidente Juárez" de la Universidad Michoacana de San Nicolás de Hidalgo para su posterior procesamiento y análisis.

Desinfección de la semilla y medios de cultivo. La desinfección de la semilla se realizó siguiendo el procedimiento reportado por Tovar et al. (2014), utilizando semillas de frutos de madroño que presentaban maduración intermedia y maduros. Se extrajeron los embriones de las semillas y se cultivaron en los medios MS (Murashige y Skoog 1962), WPM (McCown y Lloyd 1981) y 889 (Pullman et al. 2003b) en cajas de Petri de 60 × $20 \mathrm{~mm}$. El medio 889 contiene vitaminas $\mathrm{P} 889, \mathrm{AgNO}_{3}$ (nitrato de plata), y maltosa, el MS contiene sacarosa y vitaminas, y el WPM contiene vitaminas MS y tiamina. Una vez preparados los diferentes medios fueron gelificados con $8 \mathrm{~g} \mathrm{~L}^{-1}$ de agar-agar. Una vez sembrados los embriones en los medios, estos fueron colocados en un cuarto de crecimiento a $24^{\circ} \mathrm{C}$ y un fotoperiodo de $16 \mathrm{~h}$ luz y $8 \mathrm{~h}$ oscuridad evaluando el número de embriones cigóticos germinados a los 20 días de cultivo.

Inducción de callos embriogénicos. Embriones cigóticos extraídos de las semillas de frutos en un estado de madurez intermedio, previamente desinfectados, fueron cultivados en el medio MS o WPM suplementados con 0, 1, 2, 4 y $8 \mathrm{mg} \mathrm{L}^{-1}$ de 2,4-D. Una vez sembrados los embriones en los medios, estos fueron puestos en condiciones de luz $(16 / 8 \mathrm{~h})$ a una intensidad de 2.500 lux u oscuridad ( $24 \mathrm{~h}$ ) por espacio de 30 días, realizando dos subcultivos cada tres semanas, 
para posteriormente determinar el efecto de los tres factores (medio de cultivo, concentración del 2, 4-D y luz/oscuridad) sobre la formación y crecimiento del callo embriogénico.

Observaciones microscópicas. Para determinar el estado de embriogénesis que presentaban los callos obtenidos a partir de embriones cigóticos, se realizaron observaciones al microscopio, para lo cual se colocó un fragmento de callo sobre un portaobjetos y se cubrió con una gota de agua destilada estéril, para evitar su desecación. Las observaciones se realizaron en un microscopio compuesto (Leica DM 1000) a un aumento de 10x utilizando varios filtros de luz (blanca, amarilla y roja), esto con la finalidad de corroborar si los callos eran embriogénicos y la etapa de desarrollo en la que se encontraban los embriones que los conformaban.

Análisis estadístico. Se utilizó un diseño completamente al azar. Para estudiar el efecto del medio de cultivo en la germinación de los embriones cigóticos, se utilizaron tres tratamientos que correspondieron a los tres medios empleados (P88; MS y WPM), la unidad experimental consistió en una caja petri con diez embriones y cinco repeticiones; mientras que para la inducción de embriones somáticos se utilizaron cinco tratamientos que correspondieron a las concentraciones del 2,4-D: 0, 1, 2, 4 y $8 \mathrm{mg} \mathrm{L}^{-1}$, fungiendo la concentración de $0 \mathrm{mg} \mathrm{L}^{-1}$ como testigo, en donde la unidad experimental consistió en una caja petri con cinco embriones y se realizaron cinco repeticiones, tanto para la condición de luz como de oscuridad. Los resultados obtenidos se sometieron a un análisis de varianza y comparación de medias (prueba de Tukey $P \leq 0,05)$ utilizando el paquete estadístico Java Memory Profiler del SAS (JMP versión 7, año 2008).

\section{RESULTADOS}

Efecto del medio de cultivo sobre la germinación de embriones cigóticos. Los resultados indican que el medio de cultivo tuvo efecto sobre la geminación de los embriones cigóticos, pues se observó que de los tres medios utilizados, en el WPM se alcanzó un mayor número de embriones germinados con un $58 \%( \pm 2,91)$, con respecto al Pullman 889 y MS donde la germinación fue de $0( \pm 1,13)$ y $4 \%$ $( \pm 0,40)$, respectivamente.

Efecto del 2,4-D y condiciones de cultivo sobre la inducción de callos embriogénicos en el medio MS. Los resultados obtenidos del análisis de varianza para formación y crecimiento de callo embriogénico en medio MS bajo condiciones de luz, indicaron que ninguna de las diferentes concentraciones del 2,4-D tuvo efecto sobre dicho proceso, no obteniendo callos (datos no mostrados). De manera contraria, el análisis de varianza para la condición de oscuridad, mostró diferencias significativas, observándose que hay un mayor número de embriones con formación y crecimiento de callo, donde la concentración de $1 \mathrm{mg} \mathrm{L}^{-1}$ del regulador fue la mejor con 1,4 explantes, por unidad experimental, que formaron callos con un diámetro aproximado de $0,1 \mathrm{~mm}$, seguido de las concentraciones de 2 y $4 \mathrm{mg} \mathrm{L}^{-1}$, las cuales fueron estadísticamente iguales entre sí, pero diferentes al testigo (0 $\left.\mathrm{mg} \mathrm{L}^{-1}\right)$ (figura 1).

Efecto del 2,4-D y condiciones de cultivo sobre la inducción de callos embriogénicos en el medio WPM. Los embriones cultivados en medio WPM y en condiciones de luz, mostraron diferencias significativas, tanto para la formación
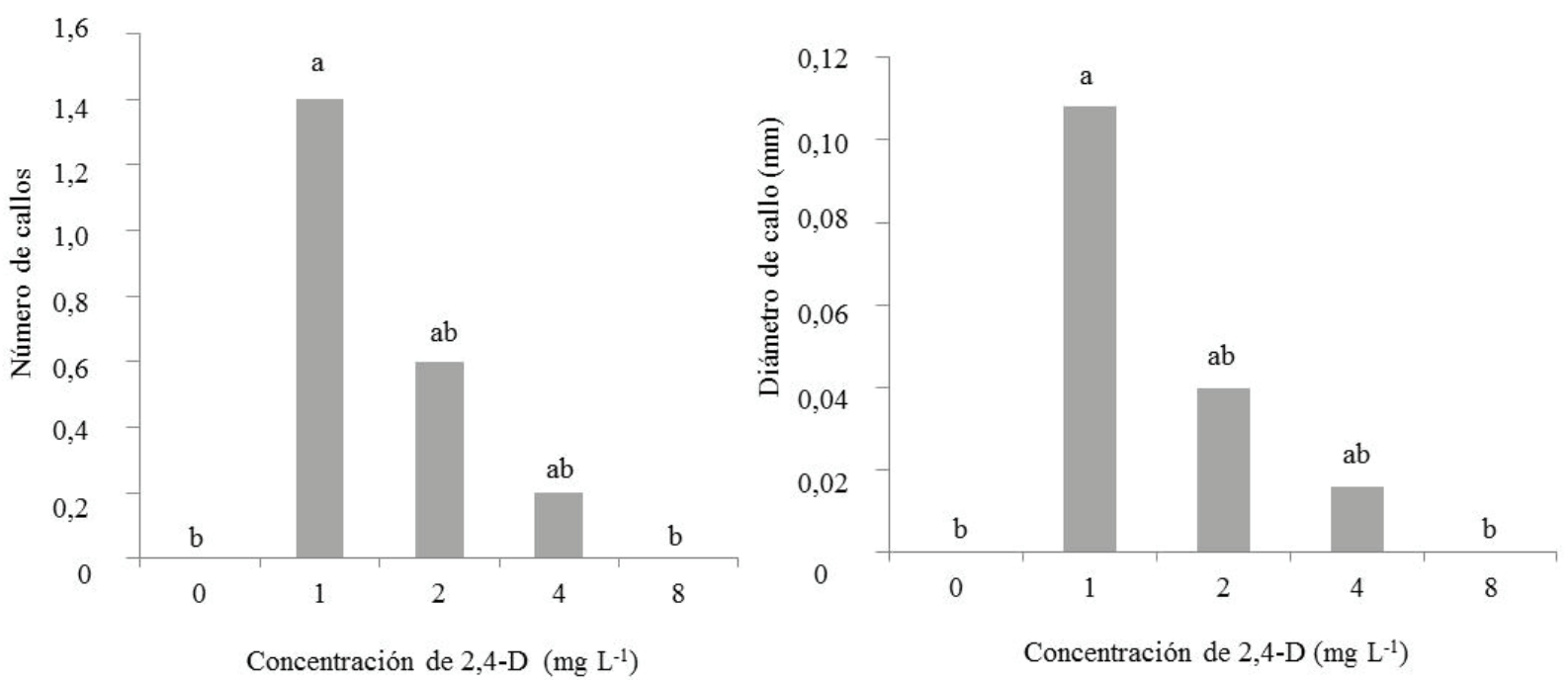

Figura 1. Efecto de la concentración de 2,4-D (0, 1, 2, 4 y $\left.8 \mathrm{mg} \mathrm{L}^{-1}\right)$ sobre el número (izquierda) y crecimiento (derecha) de callo embriogénico bajo oscuridad obtenidos de embriones zigóticos de madroño crecidos en medio MS. Valores con la misma letra son estadísticamente iguales (Tukey, $\alpha=0,05$ ).

Effect of 2,4-D (0, 1, 2, 4 and $\left.8 \mathrm{mg} \mathrm{L}^{-1}\right)$ concentration on number (left) and growth (right) under dark conditions of embryogenic callus developed from zygotic embryos of arbutus grown on MS medium. Values with the same letter are non-significant (Tukey, $\alpha 0.05$ ). 
de callo embriogénico como para el crecimiento de este, observando una mayor inducción y crecimiento de callo a concentraciones de 1 o $2 \mathrm{mg} \mathrm{L}^{-1}$ de 2,4-D, con un promedio de 3,3 a 3,9 explantes por unidad experimental que formaron callos con un diámetro aproximado de $0,25 \mathrm{~mm}$ (figura 2A); seguido de las concentraciones de 4 y $8 \mathrm{mg}$ $\mathrm{L}^{-1}$, en los cuales se observó una inducción y crecimiento de 2,0 a 2,3 explantes por unidad experimental que formaron callos con un crecimiento de 0,7 a $0,1 \mathrm{~mm}$.

En referencia a los resultados de la inducción y crecimiento de tejido calloso obtenido a partir de embriones cigóticos cultivados en medio WPM, en condiciones de oscuridad; el análisis estadístico mostró diferencias signi- ficativas, se observó que en la concentración de $1 \mathrm{mg} \mathrm{L}^{-1}$ de 2,4-D fue donde se obtuvo el mayor número de embriones por unidad experimental (3) y con un mayor diámetro de crecimiento $(0,2 \mathrm{~mm})$, seguido de las concentraciones 4,8 y $2 \mathrm{mg} \mathrm{L}^{-1}$, las cuales fueron estadísticamente iguales entre sí (figura 2B).

En cuanto al aspecto físico de los callos embriogénicos crecidos en oscuridad y posteriormente en luz, se observó una mayor poliferación de estos a concentraciones bajas de 2,4-D ( $\left.1 \mathrm{mg} \mathrm{L}^{-1}\right)$, en comparación con los crecidos en luz. Sin embargo, conforme aumentó la concentración del regulador de crecimiento y el tiempo de oscuridad hubo una mayor oxidación de los tejidos (figura 3 ).
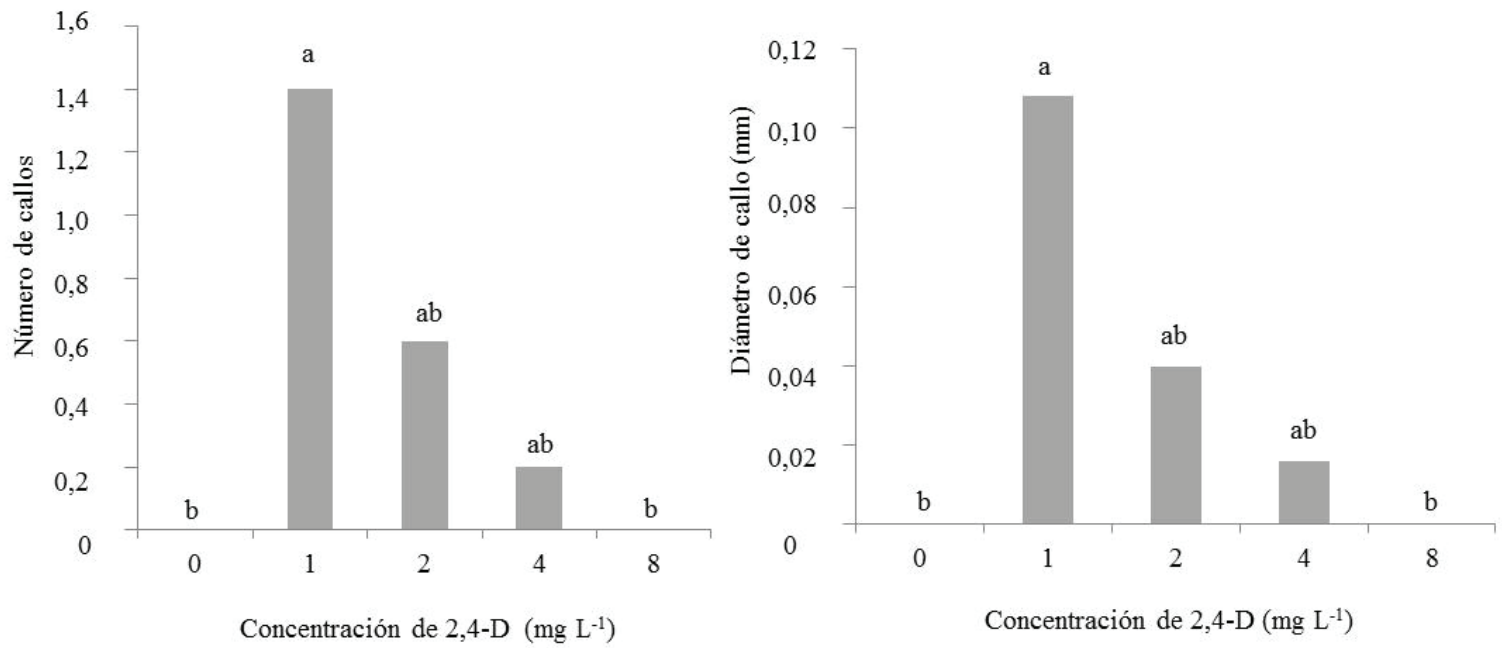

Figura 2. Efecto de la concentración de 2,4-D $\left(0,1,2,4\right.$ y $\left.8 \mathrm{mg} \mathrm{L}^{-1}\right)$ y el medio WPM, sobre la formación (izquierdo) y crecimiento (derecho) de callo embriogénico en condiciones de luz (A) y oscuridad (B), obtenidos a partir de embriones cigóticos de madroño. Valores con la misma letra son estadísticamente iguales (Tukey, $\alpha=0,05$ ).

Effect of 2,4-D (0, 1, 2, 4 and $\left.8 \mathrm{mg} \mathrm{L}^{-1}\right)$ concentration and WPM medium, on number (left) and growth (right) under light (A) and dark (B) conditions of embryogenic callus developed from zygotic embryos of arbutus. Values with the same letter are non-significant (Tukey, $\alpha$ 0.05).

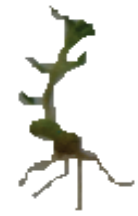

$\mathbf{0}$

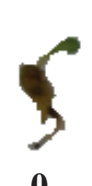

0

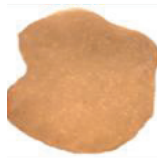

1

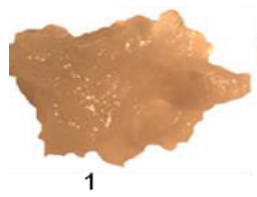

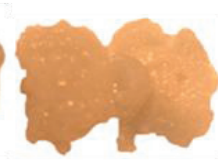

2

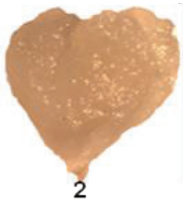

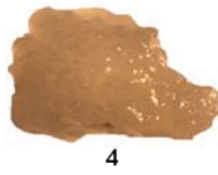

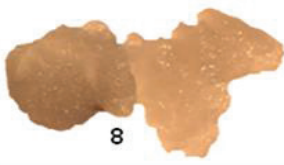

LUZ
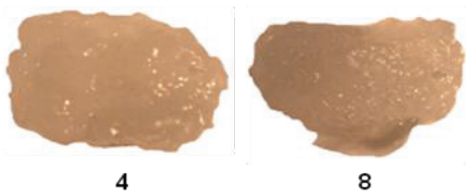

OSCURIDAD

Figura 3. Efecto del 2,4-D (0, 1, 2, 4 y $\left.8 \mathrm{mg} \mathrm{L}^{-1}\right)$ sobre la inducción de tejido calloso de embriones cigóticos de madroño, bajo condiciones de luz y oscuridad, en el medio WPM. on WP medium.

Effect of 2,4-D $\left(0,1,2,4\right.$ and $\left.8 \mathrm{mg} \mathrm{L}^{-1}\right)$ concentration on callus induction from arbutus zygotic embryos, under light and dark conditions, 
La visualización microscópica de los callos embriogénico, crecidos en un medio WPM en condiciones de oscuridad, reveló que contenían una gran cantidad de embriones somáticos en estado globular, de corazón y de torpedo (figura 4), demostrando así, que es posible obtener masas embrionarias a partir de embriones cigóticos maduros de madroño, en medio WPM suplementado con auxinas (2,4-D) y crecidos en oscuridad. En el medio WPM, en cambio, esta respuesta fue limitada en condiciones de luz donde solo se observaron embriones globulares y nula en el medio MS, pues el tejido calloso que se logró obtener rápidamente se oxidó y necrosó.
El análisis de la interacción del medio de cultivo, condición lumínica y concentración del regulador de crecimiento, sobre la formación de callo embriogénico, mostró que la mejor respuesta se obtuvo en los explantes crecidos en el medio de cultivo WPM adicionado con 2 o $1 \mathrm{mg} \mathrm{L}^{-1}$ de 2,4-D y cultivados en condiciones de luz, seguidos de los cultivados en oscuridad en bajas concentraciones de 2 , 4-D ( $\left.1 \mathrm{mg} \mathrm{L}^{-1}\right)$, o bien en luz y oscuridad con altas concentraciones del regulador ( 4 y $8 \mathrm{mg} \mathrm{L}^{-1}$ ), mientras que la menor respuesta se dio en el medio MS (figura 5).

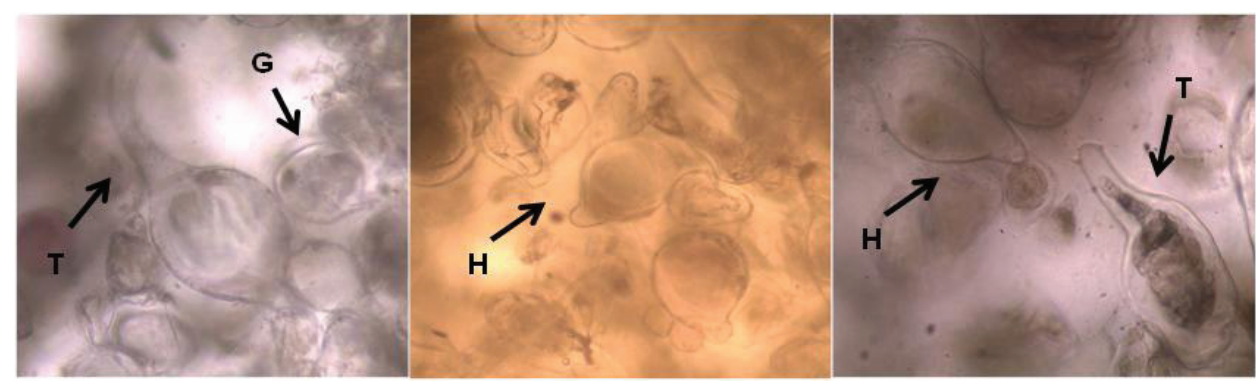

Figura 4. Observaciones microscópicas de embriones somáticos de madroño presentando los estados: globular $(\mathrm{G})$, corazón (H) y torpedo (T); observados a un aumento de 10x y con filtros de luz blanca (costados) y amarilla (centro).

Microscopic observations of arbutus somatic embryos presenting three different stages: globular (G), heart (H) and torpedo (T), observed at a $10 \%$ increase under white (left and right sides) and yellow (center) light filters.

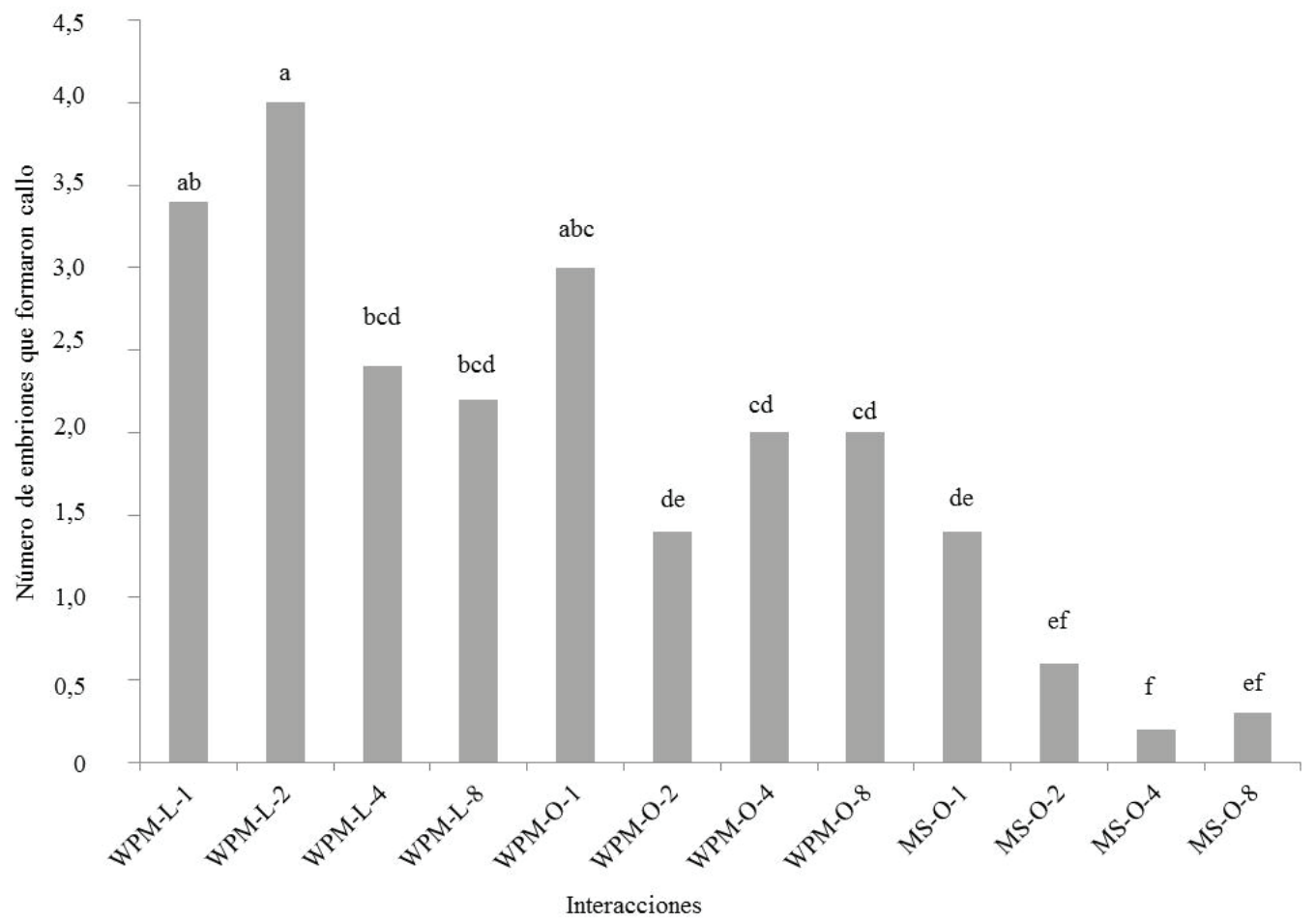

Figura 5. Efecto de la interacción de la concentración del 2,4-D, el medio de cultivo (WPM, MS) y factores de luz/oscuridad, sobre la formación de callo embriogénico obtenidos a partir de embriones cigóticos de madroño.

Interaction response among tissue culture media (WPM and MS), environment (lightness = L, darkness = D), and 2,4-D concentration $(1,2,4$ and $8 \mathrm{mg} \mathrm{L}^{-1}$ ) on the formation of embryogenic callus developed from arbutus zygotic embryos. Values with the same letter are non-significant (Tukey, $\alpha 0.05$ ). 


\section{DISCUSIÓN}

En este estudio se observa claramente que aunque se ha reportado que las semillas de madroño germinan muy bien en el medio MS (Tovar et al. 2014), los embriones cigóticos disminuyen su germinación en él, observándose una mayor respuesta en el medio WPM, que en los medios MS y 889. En el medio WPM se ha logrado la micropropagación de una gran cantidad de plantas leñosas como la azalea (Anderson 1984), el oxidendro (Banko y Stefani 1989) y el arándano (Isutsa et al. 1994), así como el madroño texano (Arbutus texana HBK) utilizando brotes apicales cultivados en medio WPM, adicionado con sales MS y 2,5 o $5 \mathrm{mg} \mathrm{L}^{-1}$ de BA (Mackay 1996). Esto se debe probablemente a la especificidad del medio, pues como se mencionó antes, el medio Pullman 889 (Pullman et al. 2003b) es específico para coníferas, el MS para el establecimiento de callo de tabaco, mientras que el WPM es utilizado para plantas leñosas, entre la que destaca el madroño texano, lo cual es relevante ya que en estudios de morfogénesis in vitro en árboles se ha observado la importancia que guarda el medio de cultivo y el desarrollo de los embriones en la generación de órganos o embriones somáticos (Cairney et al. 2000), ya que muchas especies leñosas son recalcitrantes a los métodos de regeneración in vitro (Minocha et al. 1999).

La adición del 2,4-D al medio de cultivo fue fundamental en la inducción y desarrollo de los callos embriogénicos de madroño, siendo más efectivas las respuestas morfogenéticas en el medio WPM, que la observada en MS. Estos resultados concuerdan con lo observado por Li et al. (1998), quienes lograron la regeneración de plantas de cacao (Theobroma cacao L.) vía embriogénesis somática de 19 diferentes genotipos, utilizando medio WPM adicionado con $22,7 \mu \mathrm{M}$ de tidiazuron, $9 \mu \mathrm{M}$ de 2,4-D y $1,4 \mu \mathrm{M}$ de cinetina, medio en el que se logró la formación de embriones hasta en un $100 \%$ de los explantes utilizados. Sin embargo, difieren de los reportados por Gomes y Canhoto (2009), donde encuentran que la micropropagación de Arbutus unedo L. vía organogénesis utilizando como explantes brotes apicales de plantas adultas, es más efectiva en un medio conteniendo los macronutrientes AD (Anderson 1984) y los micronutrientes MS (Murashige y Skoog 1962), adicionado con $9,4 \mu \mathrm{M}$ de BA y $0,089 \mu \mathrm{M}$ de sacarosa. Uno de los trabajos clásicos en coníferas es el de Pullman et al. (2003b), quienes han creado un medio específico para obtención de embriones somáticos de varias especies de Pinus, denominado medio básico P889, rico en maltosa y nitrato de plata, así como adicionado con carbón activado y reguladores de crecimiento como el ácido naftalenacético $\left(2 \mathrm{mg} \mathrm{L}^{-1}\right)$, bencil-amino purina $\left(0,63 \mathrm{mg} \mathrm{L}^{-1}\right)$, cinetina $\left(0,61 \mathrm{mg} \mathrm{L}^{-1}\right)$ y brasinolido $(0,1 \mu \mathrm{M})$.

Además del medio de cultivo y los reguladores de crecimientos utilizados en la iniciación de los cultivos embriogénicos de madroño, se observó que la condición lumínica es importante para el crecimiento y desarrollo de los callos embriogénico, y aun cuando en luz como en oscuridad se logra inducir callos, es la condición de oscuridad la que permite el crecimiento consecutivo de estos (figura 5) ya que los callos generados en luz después del segundo subcultivo presentaron problemas de oxidación (datos no mostrados), dificultando su crecimiento y desarrollo subsecuente. En contraparte, los callos crecidos en oscuridad y posteriormente subcultivados en luz presentaron el mejor desarrollo embrionario (figuras 4 y 5 ). Esto se debe probablemente a que la luz es un factor que dispara la producción de compuestos fenólicos en los embriones cigóticos de madroño y, como consecuencia, su oxidación, dificultando los procesos embriogénicos y la muerte progresiva de los explantes. Trabajos que concuerdan con estos resultados son aquellos en los que se han utilizado plantas herbáceas como Triticum aestivum L. (Miroshnichenko et al. 2009) y Fragaria vesca L. (Biswas et al. 2007); y especies leñosas como Coffea arabica L. (Gatica et al. 2008) y Vitis vinifera L. (GŏkTangolar et al. 2008), donde se encontró que la inducción de la embriogénesis in vitro; utilizando embriones inmaduros, maduros y hojas, fue influenciada por la composición del medios, el genotipo, la edad del explante y las condiciones de luz, donde se generan mayor número de embriones somáticos en condiciones de oscuridad. Las plantas leñosos se han caracterizado por ser más recalcitrantes que las herbáceas al proceso de embriogénesis somática (von Aderkas y Bonga 2000), pues poseen una compleja red de factores fisiológicos, morfológicos, bioquímicos y moleculares involucrados en la formación de los embriones somáticos (Komamine et al. 2005).

\section{CONCLUSIONES}

La embriogésis somática es una herramienta biotecnológica que puede ser utilizada para la propagación de especies de importancia económica y ecológica como el madroño, en donde la composición del medio de cultivo y la concentración de $1 \mathrm{mg} \mathrm{L}^{-1}$ del regulador de crecimiento 2, 4-diclorofenoxiacético es fundamental para la formación de callo embriogénico y el subsecuente desarrollo de embriones somáticos. La iniciación de los tejidos callosos de madroño es potenciada al colocar los embriones cigóticos en condiciones de oscuridad y posteriormente en luz, conteniendo tejidos con un alto potencial para el estudio de procesos morfogenéticos en esta especie.

\section{AGRADECIMIENTOS}

Al Consejo Nacional de Ciencia y Tecnología (CONACyT) por la beca de maestría núm. 239177, otorgada a Violeta Tovar Rocha, al Programa de Mejoramiento del Profesor (PROMEP-SEP) y al Consejo de Investigación Científica (CIC) de la Universidad Michoacana de San Nicolás de Hidalgo, por el apoyo económico otorgado a Ma. del Carmen Rocha Granados, mediante los proyectos PTC-292 y CIC-2011-12. 


\section{REFERENCIAS}

Anderson WC. 1984. A revised tissue culture medium for shoot proliferation of rhododendron. Journal of the American Society for Horticultural Science 109: 343-347.

Banko TJ, MA Stefani. 1989. In vitro propagation of Oxydendron arboretum from mature trees. HortScience 24: 683-685.

Biswas MK, R Islam, M Hossain. 2007. Somatic embryogenesis in strawberry (Fragaria sp.) through callus culture. Plant Cell Tissue and Organ Culture 90:49-54.

Cairney J, N Xu, J Mackay, J Pullman. 2000. Special symposium: In vitro plant recalcitrance transcript profiling: A tool asses the development of conifer embryos. In vitro Cellular Development Biology Plant 36: 155-162.

Cui SX, W Wang, CL Zhang. 2002. Plant regeneration from callus cultures in two ecotypes of reed grass (Phragmites communistrinius). In Vitro Cellular and Developmental Biology - Plant 38:325-329.

Eke ChR, P Akomeah, OAsemota. 2005. Somatic embryogenesis in date palm (Phoenix dactylifera L.) from apical meristem tissues from 'zebia' and 'loko' landraces. African Journal of Biotechnology 4 (3): 244-246.

Gamborg OL, F Constabel, RA Miller. 1970. Embryogenesis and production of albino plants from cell cultures of Bromusinermis. Planta 95:355-358.

Gatica AM, G Arrieta, AM Espinoza. 2008. Direct somatic embryogenesis in Coffea arabica L. cvs. Caturra and catuaí: Effect of triacontanol, light conditions, and medium consistency. Agronomía Costarricense 32(1):139-147.

Gŏk-Tangolar S Büyükalaca, S Ergenoğlu. 2008. High efficiency somatic embryogenesis from immature zygotic embryos of grapevine: The effect of genotype, media, 2, 4-D, and incubation conditions. Turkish Journal of Agricultureand Forestry 32:311-317.

Gomes F, JM Canhoto. 2009. Micropropagation of strawberry tree (Arbutus unedo L.) from adult plants. In Vitro Cellular \& Developmental Biology - Plant 45:72-82.

INAFED (Instituto Nacional para el Federalismo y el Desarro1lo Municipal, MX). 2009. Enciclopedia de los Estados de México: Michoacán, Medio Físico. Gobierno del Estado de Michoacán. Consultado mar. 2013. Disponible en http:// www.e-local.gob.mx/work/templates/enciclo/michoacan

Hossain M, SM Rahman, R Islam, OI Joarder. 1993. High efficiency plant regeneration from petiole explants of Carica papaya L. through organogenesis. Plant Cell Reports 13:99-102.

Isutsa DK, MP Pitts, KW Mudge. 1994. Rapid propagation of blueberry plants using ex vitro rooting and controlled acclimatization of micropropagules. HortScience29: 1124-1126.

Jayanthi M, PK Mandal. 2001. Plant regeneration through somatic embryogenesis and RAPD analysis of regenerated plants in Tylophora indica (Burm. f. Merrill.). In Vitro Cellular and Developmental Biology - Plant 37:576-580.

Komamine A, N Murata, K Nomura. 2005. Mechanisms of somatic embryogenesis in carrot suspension culture - morphology, physiology, biochemistry, and molecular biology. In vitro Cell Development Biology Plant 41:6-10.
Lauzer D, S Dallaire, G Vincent. 2000. In vitro propagation of reed grass by somatic embryogenesis. Plant Cell Tissue and Organ Culture 60:229-234.

Li R, AH Bruneau, R Qu. 2006. Improved plant regeneration and in vitro somatic embryogenesis of St. Augustine grass (Stenotaphrum secundatum (Walt.) Kunze). Plant Breed 125:52-56.

Li Z, A Traore, S Maximova, M J Guiltinan. 1998. Somatic embryogenesis and plant regeneration from floral explants of cacao (Theobroma cacao L.) using thidiazuron. In vitro Cellular and Developmental Biology-Plant 34(4):293-299.

Mackay W A. 1996. Micropropagation of Texas madrone, Arbutus xalapensis H.B.K. HortScience 31:1028-1029.

McCown BH, G Lloyd. 1981. Woody plant medium (WPM). A mineral formulation for microculture of woody plant species. Journal of Horticultural Science 16:453.

Minocha R, DR Smith, C Reeves, KD Steele, SC Minocah. 1999. Polyamine levels during the development of zygotic and somatic embryos of Pinus radiata. Physiologia Plantarum 105:155-164.

Miroshnichenko D, M Filippov, S Dolgov. 2009. Effects of diaminozide on somatic embryogenesis from immature and mature embryos of wheat. Australian Journal of Crop Science 3(2):83-94.

Murashige T, F Skoog. 1962. A revised medium for rapid growth and bioassays with tobacco tissue cultures. Physiologia Plantarum 15: 473-479.

Nitsch JP, C Nitsch. 1969. Haploid plants from pollen grains. Science 163: 85-87.

Ocampo F, VM Núñez. 2007. Propagación in vitro de Psidium guajava mediante organogénesis directa a partir de segmentos nodales. Revista Corpoica-Ciencia y Tecnología Agropecuaria 8: 22-27.

Pullman GS, B Zhang, H Phan. 2003b.Brassinolide improves embryogenic tissue initiation in conifers and rice. Plant Cell Reports 22: 96-104.

Quiroz FR, R Rojas, RM Galaz, VM Loyola. 2006. Embryo production through somatic embryogenesis can be used to study cell differentiation in plants. Plant Cell Tissue and Organ Culture 86:285-301.

Tovar Rocha V, MC Rocha Granados, P Delgado Valerio. 2014. Influence of ripering of Arbutus xalapensis Kunth on the germination of seed and zigotic embryos. Polibotánica 37: 79-92.

Thorpe TT. 2000. Somatic embryogenesis: morphogenesis, physiology, biochemistry and molecular biology. Korean Journal Plant Tissue Culture 27:245-258.

Yemets AI, LV Klimkina, LV Tarassenko and YB Blume. 2003. Efficient callus formation and plant regeneration of goose grass (Eleusineindica L. Gaertn.). Plant Cell Reports 21:503-510.

Villlobos Arámbula VM, F Engelmann. 1995. Ex-situ conservation of plant germoplasm using Biotechnology. World Journal of Microbiology \& Biotecnology 11: 376-382.

Von Aderkas P, JM Bonga. 2000. Influencing micropropagation and somatic embryogenesis in matury trees by manipulating of phase ahnge, stress and culture environmental. Tree Physilogy 20:921-928. 
